\title{
Phytochemical screening, in vitro anti-oxidant activity, and in silico anti-diabetic activity of aqueous extracts of Ruellia tuberosa $\mathrm{L}$
}

\author{
Anna Safitri ${ }^{1,2^{*}}$, Fatchiyah Fatchiyah ${ }^{3}$, Dewi Ratih Tirto Sari $^{3}$, Anna Roosdiana ${ }^{1}$ \\ ${ }^{1}$ Chemistry Department, Brawijaya University, Malang, 65145, Indonesia \\ ${ }^{2}$ Research Center for Smart Molecules of Natural Genetic Resources (SMONAGENES), Brawijaya University, Malang, 65145, Indonesia \\ ${ }^{3}$ Biology Department, Brawijaya University, Malang, 65145, Indonesia
}

\begin{tabular}{l}
\hline ARTICLE INFO \\
\hline Received on: $17 / 09 / 2019$ \\
Accepted on: $11 / 01 / 2020$ \\
Available online: $05 / 03 / 2020$ \\
\\
\hline Key words: \\
Ruellia tuberosa L., \\
LC-HRMS, phytochemical \\
screening, DPPH, in silico, \\
$\alpha$-amylase.
\end{tabular}

\begin{abstract}
The study aimed to investigate the phytochemical profiles, in vitro antioxidant activity, and in silico molecular docking antidiabetic activity of the aqueous root extracts of Ruellia tuberosa L. The phytochemical qualitative tests revealed the positive detections of tannins, flavonoids, ascorbic acid, and phenolic compounds. Using Liquid chromatographyhigh-resolution mass spectrometry (LC-HRMS) analysis, 12 compounds were tentatively identified in the extracts. The major compounds were tentatively identified as betaine, daidzein, hispidulin, $\alpha$-linoleic acid, and 4-coumaric acid. The aqueous root extracts have high antioxidant activity with the $\mathrm{IC}_{50}$ value of $15.2 \mu \mathrm{g} / \mathrm{ml}$ against DPPH free radicals. The major putatively identified compounds were docked to human pancreatic $\alpha$-amylase protein, to investigate their inhibitory activities to this enzyme. The interaction between betaine, daidzein, and hispidulin in docking with human pancreatic $\alpha$-amylase showed different binding sites to the protein. In addition, the types of bonds involved were mostly hydrogen and hydrophobic bonds which show the interactions between three ligands and $\alpha$-amylase. Energy generated from docking between betaine, daidzein, and hispidulin with $\alpha$-amylase was $-137.6,-245.8$, and -236.7 $\mathrm{cal} / \mathrm{mol}$, respectively. This study concludes that the aqueous root extracts of $R$. tuberosa L. have prospective as an inhibitor for $\alpha$-amylase protein and to be used as antidiabetic agent. Further, in vitro and in vivo studies are needed to confirm this work.
\end{abstract}

\section{INTRODUCTION}

One of the most widespread diseases due to lifestyle problems in the 21 st century is diabetes mellitus (DM). This disease is generally classified as insulin-dependent or type $1 \mathrm{DM}$, which is initiated by destruction of the insulin-producing pancreatic $\beta$-cells, and nondependent insulin or type $2 \mathrm{DM}$, which is triggered by lifestyle-related obesity or other exogenous components (Thomas and Philipson, 2015). People with type 1 diabetes need to take insulin injection for survival (Bhattarai et al., 2019). People with type 2 diabetes are not dependent on exogenous insulin; however, they display a reduced capacity to respond to insulin or a reduced

\footnotetext{
${ }^{*}$ Corresponding Author

Anna Safitri, Chemistry Department, Brawijaya University, Malang, 65145, Indonesia; Research Center for Smart Molecules of Natural Genetic Resources (SMONAGENES), Brawijaya University, Malang, 65145, Indonesia.E-mail: a.safitri@ub.ac.id
}

sensitivity to insulin, and the high levels of insulin produced are risk factors for cancers and cardiovascular diseases (Laakso, 2019).

The total diabetes prevalence is estimated to be 463 million people in 2019 and will be rising to 578 million by 2030 (Saeedi et al., 2019). The administration of oral drugs and insulin administration are currently used either alone or in combination with antidiabetic treatments. Advances in understanding the pathophysiology of the disease and the mechanism of actions of antidiabetic drugs provide an opportunity to develop safe and effective treatments of diabetes and its complications (Chaudhury et al., 2017).

In the prevention of diabetes, drug consumption is a complementary treatment besides diet. Oral antidiabetic drugs may be useful for people who are allergic to insulin or do not use insulin injection (Verspohl, 2012). However, the use of these drugs in the long term has disadvantages, including causing acute kidney toxicity and increasing the risk of heart attack (Hu and Jia, 2019). Therefore, many efforts to develop traditional medicines 
for diabetes are mounting, in particular, in Asian countries, where natural sources are abundant (Boy et al., 2018; Khan et al., 2011; Premanath and Nanjaiah, 2015).

One of the flora that can be exploited and contains many beneficial secondary metabolites compounds is from the family of Acanthaceae (Arirudran et al., 2011). One member of the Acanthaceae family is from genus Ruellia tuberosa L. is an indigenous tropical plant that is widely grown in Asian countries, i.e., Indonesia. Previous phytochemical determination revealed that saponins, carotenoids, flavonoids, and phenols were contained in the leaves of $R$. tuberosa L. (Manikandan and Doss, 2010), which were extracted using ethanol and water. Some nutrients, including ascorbic acid and tocopherol, also present in those extracts (Manikandan and Doss, 2010). In the previous study, n-hexane root extracts of $R$. tuberosa L. roots have shown in vivo antidiabetic activity (Safitri et al., 2019a). These decrease the blood glucose concentrations, lower the levels of malondialdehyde, and show the improvements on the kidney histopathological profiles (Safitri et al., 2019a). Phytochemical examination of this study shown that n-hexane $R$. tuberosa L. root extracts contained triterpenoid compounds. Furthermore, the hydroethanolic root extracts of $R$. tuberosa L. have also shown antidiabetic capacities from their positive effects on the serum and pancreatic levels of animal diabetic models (Roosdiana et al., 2019; Safitri et al., 2019b). Phytochemical screening tests conducted on this study discovered that $R$. tuberosa L. roots extracted with ethanol and water contained flavonoids, phytosterols, and phenolic compounds (Ramadhan et al., 2019; Safitri et al., 2019c). These results were also supported by Fourier transform infrared (FTIR) and LC-MS (mass spectrometry) studies (Ramadhan et al., 2019; Safitri et al., 2019c).

Most bioactive compounds, including flavonoids, and other phenolic compounds are secondary metabolite compounds that generally dissolve in the polar solvent. Hence, in this work, water is used to extract the roots of $R$. tuberosa L. In addition, the aqueous root extracts of $R$. tuberosa L. are proposed to be safer and effective which can be used as a natural remedy. This is followed by the identification and characterization of the resultant aqueous root extracts. The characterizations conducted are phytochemical test and Liquid chromatography-high-resolution mass spectrometry (LC-HRMS). Taking into account the biological functions of the R. tuberosa L. that demonstrated earlier, the potential of antioxidant activity of the aqueous root extracts of $R$. tuberosa $\mathrm{L}$. is determined using 2,2-diphenyl-1-picrylhydrazyl (DPPH) scavenging free radical test determination. For the preliminary, the antidiabetic properties of the aqueous root extracts are determined by conducting an in silico analysis of the extract compounds. These are carried out by molecular docking between human pancreatic a-amylase and the major compounds confined in the aqueous root extracts of $R$. tuberosa L., as shown from LC-HRMS results. Inhibitors of the carbohydrate digesting enzymes, i.e., $\alpha$-amylase, are proposed to be one of the effective treatments for DM (Nair et al., 2013).

\section{MATERIALS AND METHODS}

\section{Extraction of Ruellia tuberosa L.}

The plant specimens (dried root powder) of $R$. tuberosa L. were collected from Unit Pelaksana Teknis or technical operation unit (UPT) Materia Medica, Batu, East Java, and were enclosed with a determination letter of the species. The
$R$. tuberosa L. root powder was extracted using maceration technique, with distilled water, in the volume of $4 \mathrm{x}$ dried weight, for 2 x 24 hours. The resulted extracts were collected through filtration. To obtain the concentrated extracts, a rotary evaporator vacuum was used with slow speed at $100 \mathrm{rpm}$, at $40^{\circ} \mathrm{C}-50^{\circ} \mathrm{C}$. The concentrated extracts were kept at $4^{\circ} \mathrm{C}$ for subsequent analysis.

\section{Phytochemical screening test of the aqueous root extracts of Ruellia tuberosa L.}

The phytochemical qualitative tests were conducted based on standard phytochemical determinations (Evans, 2009; Harborne, 2012). The test was conducted for the detection of flavonoids, phenolic compounds, terpenoids, ascorbic acids, saponins, steroids, tannins, and alkaloids.

\section{Antioxidant activity test of the aqueous root extracts of Ruellia tuberosa $\mathbf{L}$.}

Antioxidant activities were calculated based on the extracts of scavenging potential of the DPPH free radicals in quantitative assay. Experiments were conducted on the basis of the methods mentioned in the previous study (Safitri et al., 2019c). A stock solution $(1 \mathrm{mg} / \mathrm{ml})$ of the extracts was prepared in water, from which serial diluted solutions were made to obtain a series of concentrations of $5,10,20,30,40$, and $50 \mathrm{mg} / \mathrm{ml}$. An aliquot of solution was mixed with DPPH solution $(50 \mathrm{mg} / \mathrm{ml})$, in $3: 2$ ratio; these mixture solutions were incubated at $37^{\circ} \mathrm{C}$ for 20 minutes. The absorbance was measured at $516 \mathrm{~nm}$, and from these values, the percentages of response inhibitions were determined. Then, $\%$ inhibitions were drawn against concentration; the $\mathrm{IC}_{50}$ was calculated from the graph, using linear equation, $Y=\mathrm{ax}+\mathrm{b}$. The assay was carried out in triplicate. Ascorbic acid was used in the concentration range of $2-10 \mathrm{mg} / \mathrm{ml}$, for positive control.

Liquid chromatography-high-resolution mass spectrometry analysis of the aqueous root extracts of Ruellia tuberosa $L$.

Liquid chromatographic separation was conducted in the Laboratorium Sentral Ilmu Hayati or Central laboratory for life science (LSIH) Laboratory, Brawijaya University. Column used was a Hypersil GOLD aQ $50 \times 1 \mathrm{~mm} \times 1.9 \mathrm{~mm}$ particle size column, with an injection volume of $100 \mathrm{ml}$. Solvents used were solvent $A=0.1 \%$ formic acid in water and solvent $B=0.1 \%$ formic acid in acetonitrile, with an analytical flow rate of $40 \mathrm{ml} / \mathrm{min}$. Liquid chromatography was run for 70 minutes, and this was followed by mass spectrometric analysis in Electrospray ionization (ESI) method, positive ion mode detection, using a Thermo Scientific Q Exactive mass spectrometer. Experiments were set as follows: sheath gas $\left(\mathrm{N}_{2}\right)$ pressure $=50 \mathrm{psi}$, spray voltage $=4.5 \mathrm{kV}$, capillary temperature $=300 \mathrm{~K}$, and $m / z$ range $=50-750$. The compounds were detected using Compound Discoverer software with mzCloud MS/MS library.

\section{Ligand and protein preparation for in silico study}

The 3D structures of the aqueous root extracts of $R$. tuberosa L. compounds, such as betaine (CID 247), daidzein (CID 5281708), and hispidulin (CID 5281628), were obtained from PubChem National Center for Biotechnology Information (NCBI) database. PyRx Virtual Screening Tool software was used to minimize their energy and convert the Structure data file (SDF) format into Protein Data Bank (PDB) format. The human pancreatic alpha-amylase protein was retrieved from the Research Collaboratory 
for Structural Bioinformatics (RCSB) PDB (ID: 5kez); water and other ligands bound to protein were removed using Discovery Studio Visualizer v19.1.0.18287 program (http://3dsbiovia.com/products/).

\section{Molecular docking simulations}

Human pancreatic $\alpha$-amylase protein was docked to betaine, daidzein, and hispidulin. The HEX 8.0 software was used in this study to predict the interaction and energy binding of betaine, daidzein, and hispidulin to alpha-amylase protein. The docking results were visualized using Discovery Studio Visualizer v19.1.0.18287 program (http://3dsbiovia.com/products/).

\section{RESULTS AND DISCUSSION}

Phytochemical screening and LC-HRMS analysis of the aqueous root extracts of Ruellia tuberosa $L$.

The phytochemical investigation revealed that the aqueous root extracts of $R$. tuberosa $\mathrm{L}$. contained the presence of flavonoids, tannins, ascorbic acids, and phenolic compounds, whereas the tests for saponins, steroids, alkaloids, and terpenoids yielded negative results (Fig. 1). The phytochemical tests were conducted based on the color changes after extracts reacted with the standard reagents for secondary metabolite detection. Understanding the phytochemical constituents contained in the extracts is important to predict the biological and pharmacological activities of the plants. Flavonoids, phenolic compounds, and ascorbic acids are commonly known to have high antioxidant activity (Limwachiranon et al., 2018; Smirnoff, 2018), whereas tannins are polyphenolic compounds that can act as antimicrobial agent (Smeriglio et al., 2017).

In the previous study, the hydroethanolic root extracts of $R$. tuberosa L. positively contained flavonoids, steroids, phenolics, and ascorbic acids (Safitri et al., 2019c), whereas another study reported the positive results of tannin, lycopene, tocopherol, ascorbic acid, phenolic, and carotenoid on the hydroethanolic leaves extracts of $R$. tuberosa L. (Manikandan and Dos, 2010). These demonstrate that $R$. tuberosa L. contains many secondary metabolite compounds and also some nutrients.

Tests conducted were: (a) flavonoids, (b) phenolics, (c) ascorbic acids, (d) tannins, (e) saponins, (f) steroids, (g) terpenoids, and (h) alkaloids. Positive test results are shown in (a) to (d), and negative test results are shown in (e) to (h).

To further characterize the extracts, LC-HRMS analysis was conducted. LC-HRMS analysis led to the tentative identification of 12 compounds in the extracts (Table 1). These

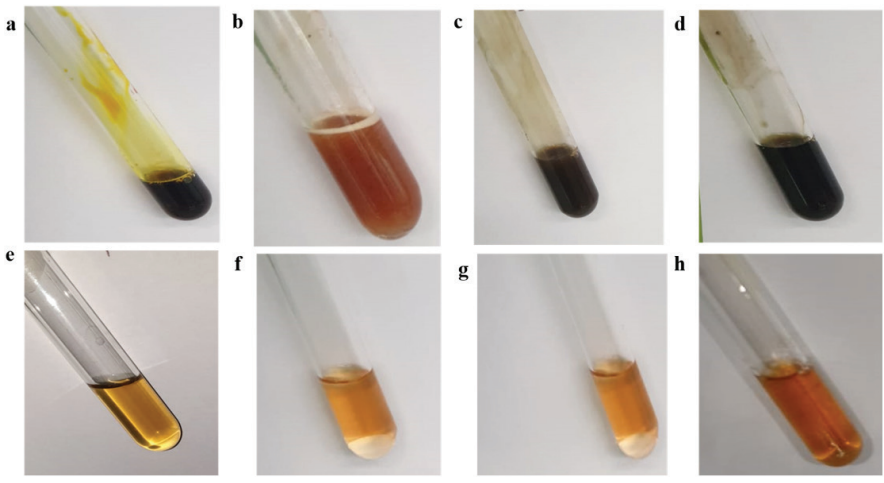

Figure 1. The phytochemical screening results of the aqueous root extracts of R. tuberosa $\mathrm{L}$. include phenolic acids, amino acids, flavonoids, and fatty acids. The predominant compounds contained in the extracts were tentatively identified as betaine [Retention time $(\mathrm{RT})=0.886$ minutes], 4-coumaric acid (RT $=6.248$ minutes), hispidulin ( $\mathrm{RT}=13.530$ minutes), daidzein $(\mathrm{RT}=16.675$ minutes $)$, and $\alpha$-linolenic acid (RT $=56.646$ minutes). Nevertheless, the compounds detected using LC-HRMS are tentatively identified, since the high-resolution MS alone is inadequate to confirm the exact identification of each compound. However, it is interesting to note that there are numerous components other than secondary metabolites such as amino acids and fatty acids found at lower concentrations in the aqueous root extracts of $R$. tuberos $a \mathrm{~L}$.

Betaine has a molecular formula $\mathrm{C}_{5} \mathrm{H}_{11} \mathrm{NO}_{2}$, established by $m / z 118.08607(\mathrm{M}+\mathrm{H})^{+}$; 4-coumaric acid with the molecular formula $\mathrm{C}_{9} \mathrm{H}_{8} \mathrm{O}_{3}$, appeared at $m / z 165.05428(\mathrm{M}+\mathrm{H})^{+}$; and hispidulin with molecular formula $\mathrm{C}_{16} \mathrm{H}_{12} \mathrm{O}_{6}$, with $\mathrm{m} / \mathrm{z} 301.06973$ $(\mathrm{M}+\mathrm{H})^{+}$. The molecular formula of daidzein and $\alpha$-linolenic acid is $\mathrm{C}_{15} \mathrm{H}_{10} \mathrm{O}_{4}$ and $\mathrm{C}_{18} \mathrm{H}_{30} \mathrm{O}_{2}$, respectively, with the $\mathrm{m} / \mathrm{z}$ emerged at $255.06450(\mathrm{M}+\mathrm{H})^{+}$and $279.23096(\mathrm{M}+\mathrm{H})^{+}$, respectively (Fig. 2). These mass spectra are in correlation with the previous published literature reporting of mass spectrometry of betaine (Kimura et al., 2017), 4-coumaric acid (Wang et al., 2012), hispidulin (Yadav and Gusta, 2013), daidzein (Andres et al., 2015), and $\alpha$-linolenic acid (Mok et al., 2018).

The previous studies have demonstrated that flavonoids and phenolic acids possess high biological and pharmacological activities (Wu et al., 2018). Hispidulin and daidzein are flavonoid compounds, whereas 4-coumaric acid is phenolic compound; these compounds have high antioxidant activity (Andres et al., 2015; Yadav and Gusta, 2013). A previous study showed that hispidulin inhibits apoptosis and causes autophagy in diabetic murine induced by high glucose diet (Wu et al., 2018). In addition, daidzein also has been reviewed to have antidiabetic activity from the evidence from clinical, preclinical, and cell culture studies (Das et al., 2018).

Betaine, the oxidation product of choline, can act as an organic osmolyte to protect cells under stress (Heidari et al., 2018). Another study pointed out that betaine has a potential application in the treatment of diabetes, by showing improvement in serum insulin and triglycerides levels of $d b / d b$ mice (Jung et al., 2013).

Table 1. LC-HRMS results of the aqueous root extracts of $R$. tuberosa L. with proposed identities of compounds with mass errors of less than $5 \mathrm{ppm}$.

\begin{tabular}{clcccc}
\hline No & $\begin{array}{l}\text { Proposed } \\
\text { Compound }\end{array}$ & $\begin{array}{c}\text { RT } \\
(\mathbf{m i n u t e s})\end{array}$ & $\begin{array}{c}\text { Experimental } \\
\boldsymbol{m} / \boldsymbol{z}\end{array}$ & $\begin{array}{c}\text { Calculated } \\
\boldsymbol{m} / \boldsymbol{z}\end{array}$ & $\begin{array}{c}\text { D } \boldsymbol{m} \\
(\mathbf{p p m})\end{array}$ \\
\hline 1 & Betaine & 0.886 & 117.07823 & 117.07879 & 4.8 \\
2 & L-phenylalanine & 1.511 & 165.07824 & 165.07871 & 2.8 \\
3 & Isoamylamine & 1.613 & 87.10449 & 87.10501 & 6.0 \\
4 & Phenmetrazine & 2.079 & 177.11460 & 177.11501 & 2.3 \\
5 & DL-tryptophan & 2.600 & 226.07304 & 226.07356 & 2.3 \\
6 & 6-Methylquinoline & 3.650 & 143.07270 & 143.07311 & 2.9 \\
7 & 4-Coumaric acid & 6.238 & 164.04644 & 164.04696 & 3.2 \\
8 & 1,5-Isoquinolinediol & 9.236 & 161.04674 & 161.04726 & 3.2 \\
9 & Hispidulin & 13.530 & 300.06189 & 300.06236 & 1.6 \\
10 & Daidzein & 16.623 & 254.05666 & 254.05707 & 1.6 \\
11 & Valerophenone & 19.262 & 162.10353 & 162.10394 & 2.5 \\
12 & $\alpha$-Linolenic acid & 56.646 & 278.22312 & 278.22359 & 1.7 \\
\hline
\end{tabular}


$\mathbf{a}$

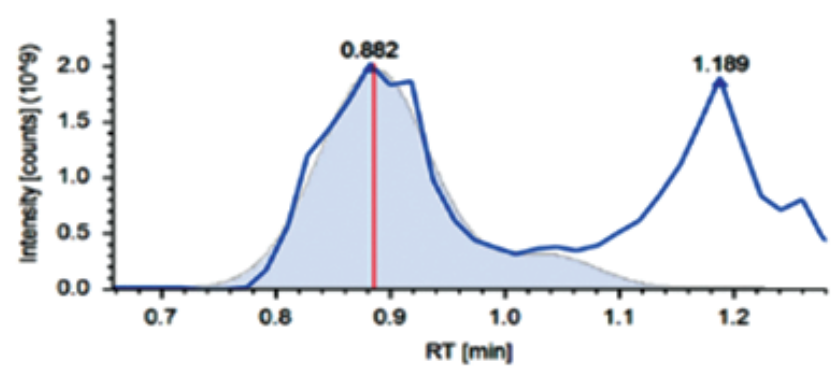

b

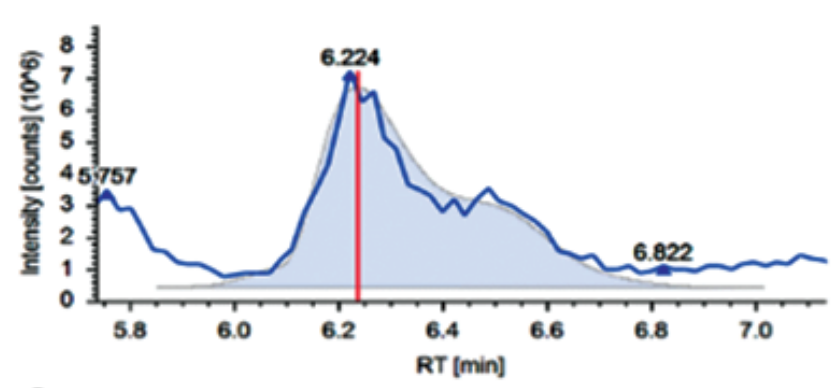

c

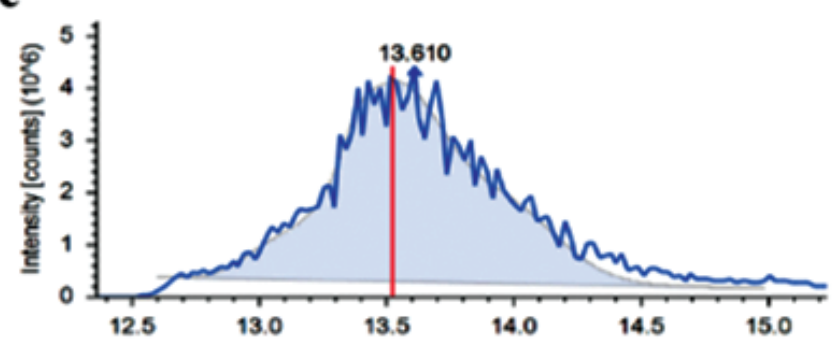

d

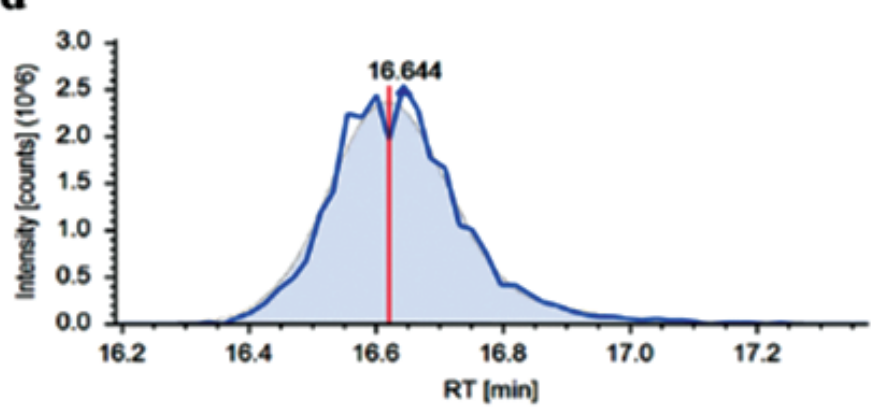

e

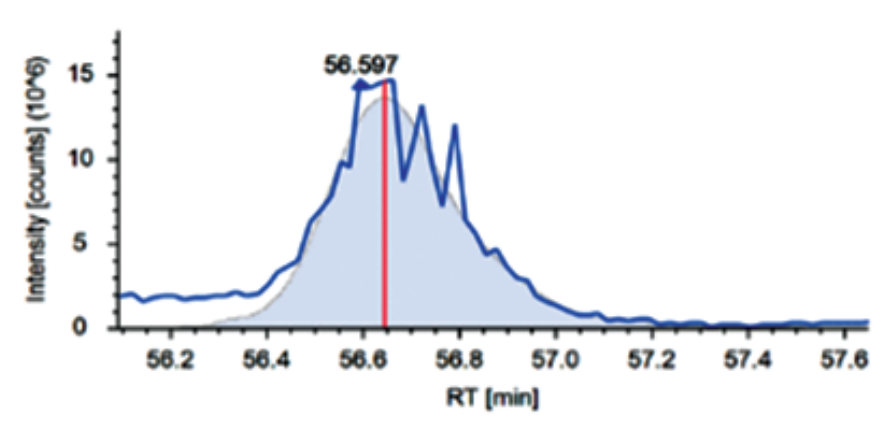

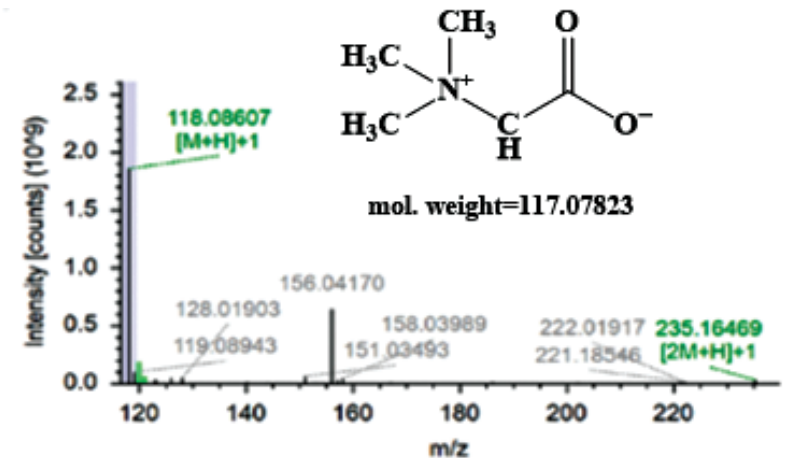
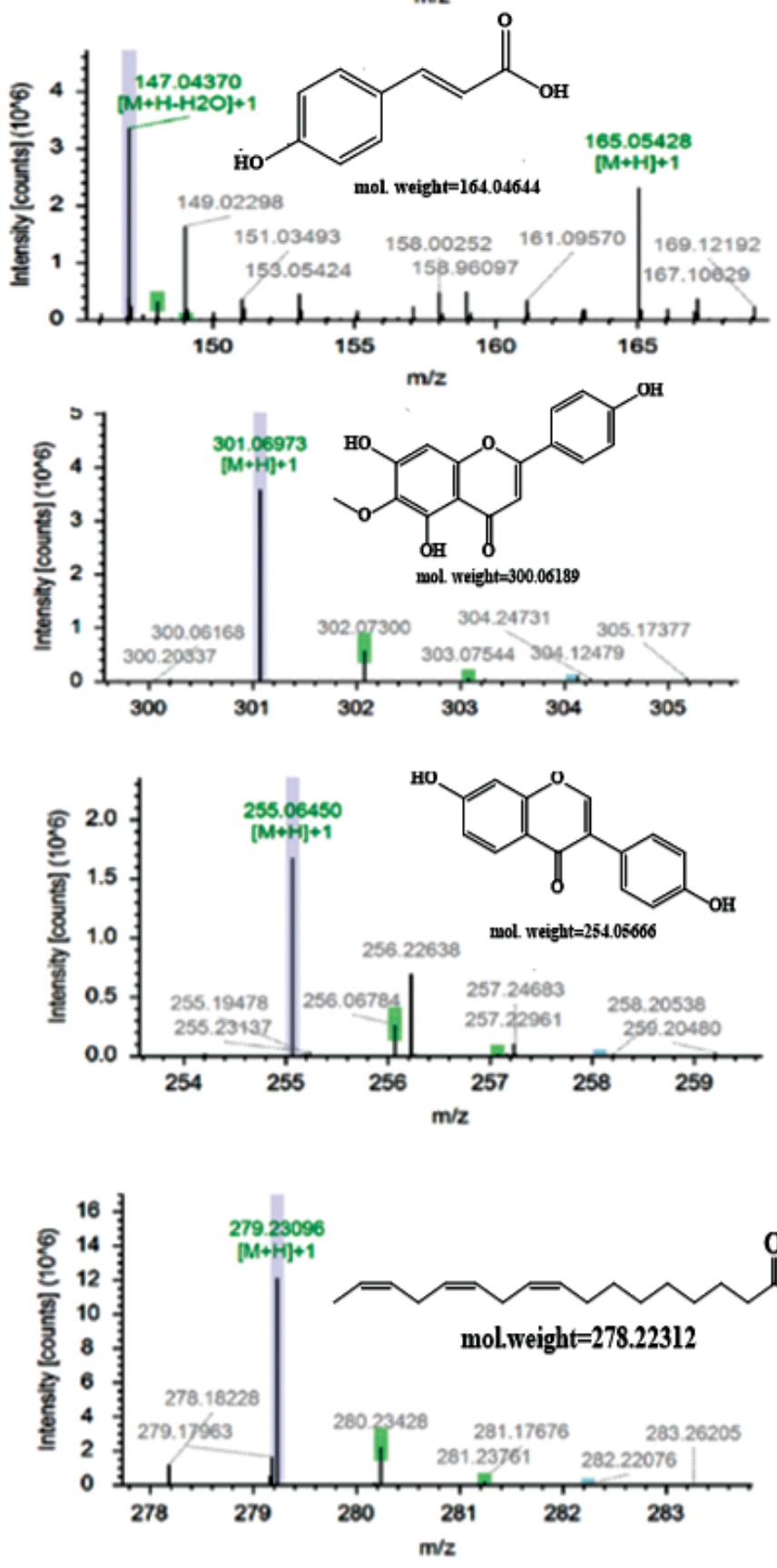

Figure 2. LC-HRMS chromatograms and mass spectra of (a) betaine, (b) 4-coumaric acid, (c) hispidulin, (d) daidzein, and (e) $\alpha$-linolenic acid, of the aqueous root extracts of R. tuberosa L. Figures show experimental molecular weight based on the mass spectra. 
Finally, $\alpha$-linolenic acid is an essential fatty acid that is needed in human diet (Calder, 2015).

These have proved that water as single solvent can be applied for the extraction of secondary metabolite compounds from plants. Furthermore, since the compounds contained in the aqueous root extracts of $R$. tuberosa L have many biological capacities, the extracts have a potency to be used as natural remedy.

\section{Antioxidant activity of the aqueous root extracts of Ruellia tuberosa $\mathrm{L}$.}

Many human disorders such as neurodegenerative diseases, cancer, and diabetes are frequently caused by the involvement of free radicals. In treatment of those diseases, the antioxidants through their scavenging power are needed. Many plants used for treating diabetes were reported to have antioxidant activities; therefore, it is necessary to confirm the antioxidant activities of selected medicinal plants in vitro using reliable methods such as radical scavenging activity and reducing power. DPPH free radical scavenging assay is a rapid and effective technique to determine the antioxidant action of a specific compound or plant extracts. The antioxidant activity of the aqueous root extracts of $R$. tuberosa $\mathrm{L}$. $\left(\mathrm{IC}_{50}\right.$ of $\left.15.22 \mathrm{mg} / \mathrm{ml}\right)$ is lower compared to that the antioxidant activity of ascorbic acid $\left(\mathrm{IC}_{50}\right.$ of $\left.2.48 \mathrm{mg} / \mathrm{ml}\right)$, as shown in Table 2. However, with the $\mathrm{IC}_{50}$ value of $15.22 \mathrm{mg} / \mathrm{ml}(<50 \mathrm{mg} /$ $\mathrm{ml}$ ), the aqueous root extracts of $R$. tuberosa L. are still considered which possess high antioxidant capacity (Molyneux, 2004). These are in agreement with results from previous studies which shown that $R$. tuberosa L. extracted with organic solvents possesses biological capacities, such as antioxidant, anti-inflammation, and anticancer (Chothani et al., 2010).

Table 2. Antioxidant activity of the aqueous root extracts of $R$. tuberosa L.

\begin{tabular}{|c|c|c|c|c|c|c|}
\hline No & $\begin{array}{c}\text { Sample } \\
\text { concentration } \\
(\mathbf{m g} / \mathbf{m l})\end{array}$ & $\begin{array}{c}\text { Sample } \\
\text { inhibition } \\
\text { activity }(\%)\end{array}$ & $\begin{array}{c}\mathrm{IC}_{50} \text { of } \\
\text { sample } \\
(\mathrm{mg} / \mathrm{ml})^{*}\end{array}$ & $\begin{array}{l}\text { Ascorbic acid } \\
\text { concentration } \\
(\mathrm{mg} / \mathrm{ml})\end{array}$ & $\begin{array}{c}\text { Ascorbic acid } \\
\text { inhibition activity } \\
(\%)\end{array}$ & $\begin{array}{c}\mathrm{IC}_{50} \text { of } \\
\text { ascorbic acid } \\
(\mathrm{mg} / \mathrm{ml})^{*}\end{array}$ \\
\hline 1 & 5 & 41.4 & & 2 & 48.9 & \\
\hline 2 & 10 & 47.4 & & 4 & 50.4 & \\
\hline 3 & 20 & 55.0 & $15.22 \pm 0.08$ & 6 & 53.4 & $2.48 \pm 0.77$ \\
\hline 4 & 30 & 58.6 & $R^{2}=0.9857$ & 8 & 56.3 & $R^{2}=0.9803$ \\
\hline 5 & 40 & 74.4 & & 10 & 57.8 & \\
\hline
\end{tabular}

*Averages and standard deviation from three replicates from two independent experiments are shown.

Table 3. Interaction of human pancreatic $\alpha$-amylase with betaine, daidzein, or hispidulin by in silico analysis.

\begin{tabular}{|c|c|c|c|c|}
\hline Compound & Interaction* & Chemistry bond & Types & Energy $(\mathrm{cal} / \mathrm{mol})$ \\
\hline \multirow[t]{5}{*}{ Betaine } & :LIG1:N - A:ASP402:OD1 & Electrostatic & Attractive charge & -137.6 \\
\hline & A:ARG398:HE - :LIG1:O & Hydrogen bond & Conventional hydrogen bond & \\
\hline & :LIG1:H - A:GLY334:O & Hydrogen bond & Carbon hydrogen bond & \\
\hline & :LIG1:H - A:GLY334:O & Hydrogen bond & Carbon hydrogen bond & \\
\hline & :LIG1:H - A:THR11:O & Hydrogen bond & Carbon hydrogen bond & \\
\hline \multirow[t]{7}{*}{ Daidzein } & A:ARG389:NH1 - :LIG1 & Electrostatic & Pi-Cation & -245.8 \\
\hline & A:ARG389:NH1 - :LIG1 & Electrostatic & Pi-Cation & \\
\hline & :LIG1:O - A:TRP388 & Other & Pi-Lone Pair & \\
\hline & A:TRP388 - :LIG1 & Hydrophobic & Pi-Pi stacked & \\
\hline & A:TRP388 - :LIG1 & Hydrophobic & Pi-Pi stacked & \\
\hline & :LIG1 - A:ARG389 & Hydrophobic & Pi-Alkyl & \\
\hline & :LIG1 - A:ARG389 & Hydrophobic & Pi-Alkyl & \\
\hline \multirow[t]{10}{*}{ Hispidulin } & A:SER3:HG - :LIG1:O & hydrogen bond & Conventional hydrogen bond & -236.7 \\
\hline & A:ASN5:HN - :LIG1:O & Hydrogen bond & Conventional hydrogen bond & \\
\hline & A:GLY9:HN - :LIG1:O & Hydrogen bond & Conventional hydrogen bond & \\
\hline & :LIG1:H - :LIG1:O & Hydrogen bond & Conventional Hydrogen bond & \\
\hline & :LIG1:H - A:GLY334:O & Hydrogen bond & Conventional hydrogen bond & \\
\hline & A:PRO4:CD - :LIG1:O & Hydrogen bond & Carbon hydrogen bond & \\
\hline & A:PHE335 - :LIG1 & Hydrophobic & Pi-Pi T-shaped & \\
\hline & :LIG1 - A:PRO4 & Hydrophobic & Pi-Alkyl & \\
\hline & :LIG1 - A:PRO4 & Hydrophobic & Pi-Alkyl & \\
\hline & :LIG1 - A:PRO4 & Hydrophobic & Pi-Alkyl & \\
\hline
\end{tabular}

*The H-donor in betaine-human a-amylase interaction; positive ion in Pi-cation, lone pair in Pi-lone pair, and Pi-orbitals in daidzein-human a-amylase interaction; and $\mathrm{H}$-donor in hydrogen bonds and Pi-orbitals in hispidulin-human a-amylase interaction were written in bold letters. 
a1

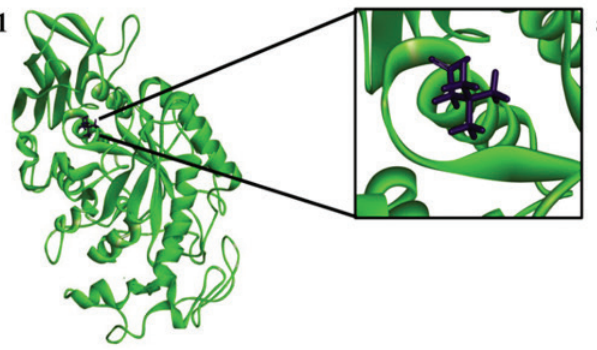

b1

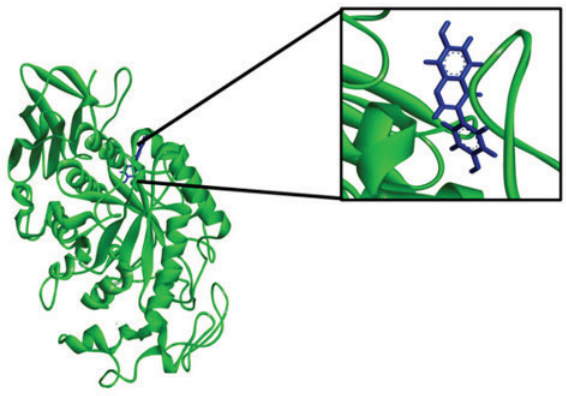

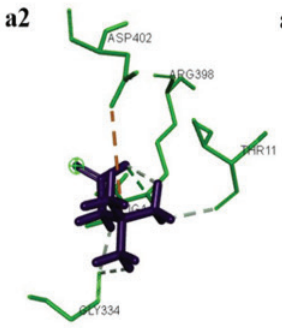

b2

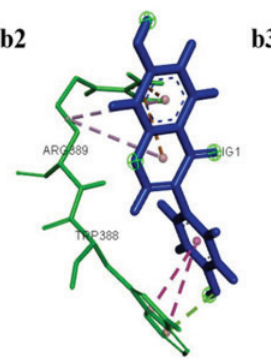

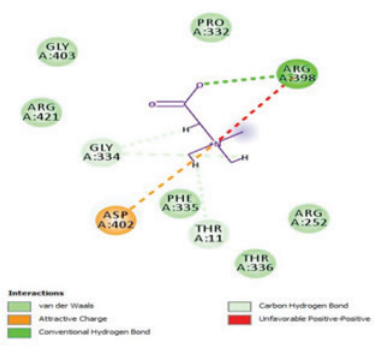

c1

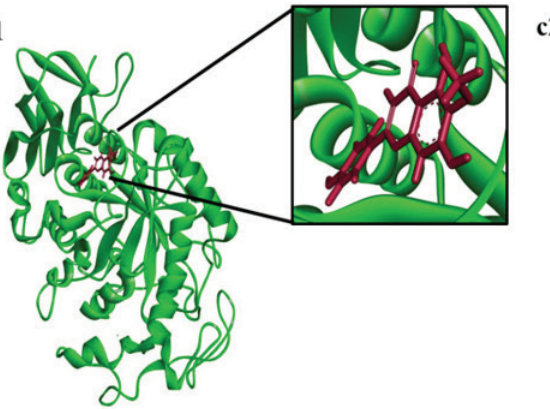

c2

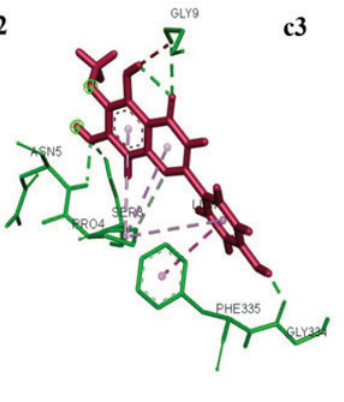

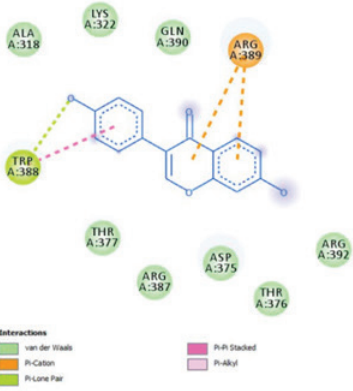

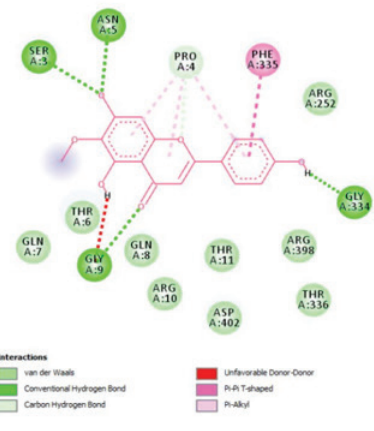

Figure 3. In silico molecular docking results of interactions between human pancreatic a-amylase protein with (a) betaine, (b) daidzein, and (c) hispidulin. Number 1 shows an overview of betaine/daidzein/hispidulin-human pancreatic a-amylase complex; number 2 shows the 3D structure of betaine/daidzein/hispidulin-human pancreatic a-amylase complex; and number 3 shows the 2D structure of betaine/daidzein/hispidulin-human pancreatic a-amylase complex.

\section{In silico molecular docking analysis}

The molecular docking between betaine, daidzein, and hispidulin to human pancreatic $\alpha$-amylase protein has been conducted to investigate further interaction between the protein and ligands. Ligands chosen for the study are betaine, daidzein, and hispidulin. It is predicted that these compounds have the ability to bind human pancreatic $\alpha$-amylase; thus, they have antidiabetic capacity.

The ligands-protein interaction was presented by the binding sites on amino acid residue and the types of chemistry bond formed as shown in Table 3. Four amino acid residues in domain A of human pancreatic $\alpha$-amylase were interacted with betaine (Fig. 3a): Asp402, Arg398, Thr11, and Gly 334. The energy binding of the betaine-human pancreatic $\alpha$-amylase complex was $-137.6 \mathrm{cal} / \mathrm{mol}$. Those interactions were mediated by hydrogen bond formation, either conventional hydrogen bond or carbon-hydrogen bond, and also attractive charge.

Unlike betaine, daidzein bound to different binding sites to human pancreatic $\alpha$-amylase (Fig. 3b). The daidzein-human pancreatic $\alpha$-amylase complex had a less number of interactions compared to those of betaine-human pancreatic $\alpha$-amylase complex (Table 3). Based on the molecular docking results in
Fig. 3(b), Arg389 and Trp388 were the amino acid residues that bound to daidzein by establishing Pi-alkyl and Pi-lone pair donor through hydrophobic interaction. The daidzein-human pancreatic $\alpha$-amylase complex had the energy binding of -245.8 $\mathrm{cal} / \mathrm{mol}$. Intriguingly, the interaction between hispidulin and human pancreatic $\alpha$-amylase occurred at different binding sites of the protein as well, different with those of betaine and daidzein (Fig. 3c). There were six amino acid residues interacted with hispidulin: Asn5, Ser3, Phe335, Gly334, Gly9, and Pro4. These interactions were maintained by hydrogen bonds and hydrophobic interaction. The hispidulin-human pancreatic amylase complex resulted in the energy binding of $-236.7 \mathrm{cal} / \mathrm{mol}$.

Alpha-amylase inhibitors are used as antidiabetic drugs since they can control carbohydrate breakdown and eventually reduce the rate of carbohydrate absorption from the gastrointestinal tract (Nair et al., 2013). In recent years, drugs designed to lessen blood glucose levels and to maintain glucose homeostasis from natural products are gaining popularity (Jhong et al., 2015). Many research has been conducted this area to search alternative drugs from natural materials that could normalize hyperglycemia through the downregulation of alpha-amylase activity. Nevertheless, the active mechanisms of action remain unclear. 
The different kinds of interaction affected the binding energy (Fatchiyah et al., 2017). Hydrogen bonds are important contributors for the structure and interaction of protein-protein or ligand-receptor (Chen et al., 2016; Kostal, 2016). In the drug design, hydrogen bonds are critical to obtain the specificity of the drug to protein target (Chen, et. al., 2018). In this in silico analysis, betaine-human pancreatic a-amylase interaction showed the lowest number of hydrogen and hydrophobic bonds; therefore, this complex also shown the weakest binding affinity. The highest binding affinity was shown in the daidzein-human pancreatic a-amylase complex. The in silico study conducted has supported the identification and characterization and in vitro pharmacological antioxidant activity of the aqueous root extracts of $R$. tuberosa L.

The studies on the flavonoid compounds acting as alpha-amylase inhibitors through molecular docking approach have been conducted previously (Jhong et al., 2015; Meidinna and Fatchiyah, 2019). An in silico study for the compound in the n-hexane fraction of methanolic extract (HFME) of $R$. tuberosa L. has been conducted previously, also using a-amylase as protein target (Wulan et al., 2015). Results from this study showed that betulin, compound contained in the HFME of $R$. tuberosa L., strongly inhibited $\alpha$-amylase activity, suggesting to have antidiabetic activity. Those studies have also concluded that in silico molecular docking is an effective and rapid method for investigating molecular interaction and mode of action of bioactive compounds targeting alpha-amylase activity.

\section{CONCLUSION}

This study implies that the aqueous root extracts of $R$. tuberosa L. have high antioxidant activity, and these extracts have potential as inhibitor for $\alpha$-amylase protein. Water as single solvent can be useful for secondary metabolite extraction that possesses many biological capacities. The use of LC-HRMS tentatively identified many metabolites and compounds contained in the aqueous root extracts of $R$. tuberosa L. Further analyses, including high-resolution $\mathrm{MS} / \mathrm{MS}$ and isotopic analysis, are required for positive identification of the compounds. The inhibition of alpha-amylase enzyme leads to novel discovery of plant-based therapeutic products, in particular, for diabetes. Computational molecular docking could be used as an effective supporting tool for the drug development process. To sum up, the aqueous root extracts of $R$. tuberosa L. have prospective to be utilized as natural remedy for diabetes. Further research on both the in vitro and in vivo approaches is needed to confirm this current work results.

\section{ACKNOWLEDGMENT}

This research was supported by Hibah Penelitian Unggulan, Universitas Brawijaya, Indonesia, grant number 697.1/ UN10.C10/PN/2019.

\section{REFERENCES}

Andres S, Hansen U, Niemann B, Palavinskas R, Lampen A. A rapid and sensitive profiling of free fatty acids using liquid chromatography electrospray ionization tandem mass spectrometry (LC/ESI-MS/MS) after chemical derivatization. Food Funct 2015; 6:2017-25.

Arirudran B, Saraswathy A, Krishnamurthy V. Pharmacognostic and preliminary phytochemical studies on Ruellia tuberosa L. (whole plant). Pharmacogn J 2011; 3:29-34.

Bhattarai S, Godsland IF, Misra S, Johnston DG, Oliver N. Metabolic health and vascular complications in type 1 diabetes. J Diabetes
Complicat 2019; 33:634-40.

Boy HIA, Rutilla AJH, Santos KA, Ty AMT, Yu AI, Mahboob T, Tangpoong J, Nissapatorn V. Recommended medicinal plants as source of natural products: a review. Digital Chin Med 2018; 1:131-42.

Calder PC. Functional roles of fatty acids and their effects on human health. J Parenter Enteral Nutr 2015; 39:18S-32S.

Chaudhury A, Duvoor C, Dendi VSR, Kraleti S, Chada A, Ravilla R, Marcol A, Shekhawat NS, Montales MT, Kuriakose K, Sasapu A, Beebe A, Patil N, Musham CK, Lohani GP, Mirza W. Clinical review of antidiabetic drugs: implications for type 2 diabetes mellitus management. Front Endocrinol 2017; 8:12.

Chen D, Li Y, Zhao M, Tan W, Li X, Savidge T, Guo W, Fan X. Effective lead optimization targeting the displacement of bridging receptorligand water molecules. Phys Chem Chem Phys 2018; 20:24399-407.

Chen D, Oezguen N, Urvil P, Ferguson C, Dann SM, Savidge TC. Regulation of protein-ligand binding affinity by hydrogen bond pairing. Sci Adv 2016; 2 :e1501240.

Chothani DL, Patel MB, Mishra SH, Vaghasiya HU. Review on Ruellia tuberosa (Cracker plant). Pharmacogn J 2010; 2:506-12.

Das D, Sarkar S, Bordoloi J, Wann SB, Kalita J, Manna P. Daidzein, its effects on impaired glucose and lipid metabolism and vascular inflammation associated with type 2 diabetes. Biofactors 2018; 44:407-17.

Evans WC. Trease and evans pharmacognosy. Elsevier Health Sciences, London, UK, 2009.

Fatchiyah F, Rahasta AH, Cairns JR. Virtual screening and prediction of binding of caprine CSN1S2 protein tryptic peptides to glucokinase. Acta Inform Med 2017; 25:225-31.

Harborne JB. Phytochemical methods: a guide to modern techniques of plant analysis. Chapman and Hall, New York, NY, 2012.

Heidari R, Niknahad H, Sadeghi A, Mohammadi H, Ghanbarinejad V, Ommati MM, Hosseini A, Azarpira N, Khodaei F, Farshad O, Rashidi E, Siavashpour A, Najibi A, Ahmadi A, Jamshidzadeh A. Betaine treatment protects liver through regulating mitochondrial function and counteracting oxidative stress in acute and chronic animal models of hepatic injury. Biomed Pharmacother 2018; 103:75-86.

Hu C, Jia W. Therapeutic medication against diabetes: what we have and what we expect. Adv Drug Delivery Rev 2019; 139:3-15.

Jhong C-H, Riyaphan J, Lin S-H, Weng CF. Inhibitors from naturals compounds by molecular docking in silico. Biofactors 2015; $41: 242-51$

Jung GY, Won SB, Kim J, Jeon S, Han A, Kwon YH. Betaine alleviates hypertriglycemia and tau hyperphosphorylation in $d b / d b$ mice. Toxicol Res 2013; 29:7-14.

Khan KY, Khan MA, Ahmad M, Hussain I, Mazari P, Fazal H, Ali B, Khan, IZ. Hypoglycemic potential of genus Ficus L.: a review of ten years of plant based medicine used to cure diabetes (2000-2010). J Appl Pharm Sci 2011; 1:223-7.

Kimura S, Ong M, Ichikawa S, Tomita-Yokotani K, Compatible solutes in the akinetes of the terrestrial cyanobacterium Nostoc sp. HK-01 contribute to its heat tolerance. Am J Plant Sci 2017; 8:2695-711.

Kostal J. Computational chemistry in predictive toxicology: status quo et quo vadis ? Adv Mol Toxicol 2016; 10:139-86. 27:S139-46.

Laakso M. Biomarkers for type 2 diabetes. Mol Metab 2019;

Limwachiranon J, Huang H, Shi Z, Li L, Luo Z. Lotus flavonoids and phenolic acids: health promotion and safe consumption dosages. Compr Rev Food Sci Food Saf 2018; 17: 458-71.

Manikandan A, Doss DVA. Evaluation of biochemical contents, nutritional value, trace elements, SDS-PAGE and HPTLC profiling in the leaves of Ruellia tuberosa L. and Dipteracanthus patulus (Jacq.). J Chem Pharm Res 2010; 2:295-303.

Meidinna HN, Fatchiyah F. The potential role of rosmarinic acid and sinensetin as $\alpha$-amylase Inhibitor: in silico study. J Pure Appl Chem Res 2019; 8:73-9.

Mok HJ, Lee JW, Bandu R, Kang HS, Kim K-H, Kim KP. Bioactive flavonoids in medicinal plants: structure, activity and biological fate. Asian J Pharm Sci 2018; 13:12-23. 
Molyneux P. The use of the stable free radical diphenylpicrylhydrazyl (DPPH) for estimating antioxidant activity. Songklanakarin J Sci Technol 2004; 26:211-9.

Nair SS, Kavrekar V, Mishra A. In vitro studies on alpha amylase and alpha glucosidase inhibitory activities of selected plant extracts. Eur J Exp Biol 2013; 3:128-32.

Premanath R, Nanjaiah L. Antidiabetic and antioxidant potential of Andrographis paniculata Nees. leaf ethanol extract in streptozotocin induced diabetic rats. J Appl Pharm Sci 2015; 5:69-76.

Ramadhan M, Sabarudin A, Safitri A. In vitro anti-microbial activity of hydroethanolic extracts of Ruellia tuberosa L.: eco-friendly based-product against selected pathogenic bacteria. IOP Conf Series: Earth Environ Sci 2019; 239: 012028.

Roosdiana A, Sutrisno S, Mahdi C, Safitri A. The influence of ethanolic root extracts of Ruellia tuberosa L. on pancreatic protease activity and MDA level of rats (Rattus norvegicus) induced by MLD-STZ. OP Conf Series: Earth Environ Sci 2019; 217: 012041.

Saeedi P, Petersohn I, Salpea P, Malanda B, Karuranga S, Unwin N, Colagiuri S, Guariguata L, Motala AA, Ogurtsova K, Shaw JE, Bright D, Williams R. Global and regional diabetes prevalence estimates for 2019 and projections for 2030 and 2045: results from the International Diabetes Federation Diabetes Atlas, 9th edition. Diabetes Res Clin Prac 2019; 157:107843.

Safitri A, Roosdiana A, Rosyada I, Evindasari CA, Muzayyana Z, Rachmawanti R. Phytochemicals screening and anti-oxidant activity of hydroethanolic extracts of Ruellia tuberosa L. IOP Conf Series: Mat Sci Eng 2019c; 509:012017.

Safitri A, Srihardyastutie A, Roosdiana A, Aulanni'am A, Octaviana, ANL. Effects of root extract of Ruellia tuberosa L. on kidneys of diabetic rats. J Math Fund Sci 2019a; 51:127-37.

Safitri A, Sutrisno S, Roosdiana A, Evindasari CA. Hypoglycaemic activity of hydroethanolic root extracts of Ruellia tuberosa L in diabetic rats. IOP Conf Series: J Phys 2019b; 1146:012020.
Smeriglio A, Barreca D, Bellocco E, Trombetta D. Proanthocyanidins and hydrolysable tannins: occurrence, dietary intake and pharmacological effects. Br J Pharmacol 2017; 174:1244-62.

Smirnoff N. Ascorbic acid metabolism and functions: a comparison of plants and mammals. Free Radical Biol Med 2018; 122:116-29.

Thomas CC, Philipson LH. Updates on diabetes classification. Med Clin North Amer 2015; 99:1-16.

Verspohl EJ. Novel pharmacological approaches to the treatment of type 2 diabetes. Pharmacol Rev 2012; 64:188-237.

Wang J, Yue Y-D, Tang F, Sun J. Determination of the isoflavone composition and estrogenic activity of commercial dietary supplements based on soy or red clover. Molecules 2012; 17:8872-85.

Wu F, Li S, Zhang N, Huang W, Li X, Wang M, Bai D. Hispidulin alleviates high-glucose-induced podocyte injury by regulating protective autophagy. Biomed Pharmacother 2018; 104:307-14.

Wulan DR, Utomo EP, Mahdi, C. Antidiabetic activity of Ruellia tuberosa L., role of $\alpha$-amylase inhibitor: in silico, in vitro, and in vivo approaches. Biochem Res Int 2015; 2015:9.

Yadav AK, Gupta MM. Quantitation of antitubercular compounds in Oroxylum indicum, a Thai vegetable used in the indian system of medicine. J Planar Chromatogr 2013; 26:306-11.

How to cite this article:

Safitri A, Fatchiyah F, Sari DRT, Roosdiana A. Phytochemical Phytochemical screening, in vitro anti-oxidant activity, and in silico anti-diabetic activity of aqueous extracts of Ruellia tuberosa L. J Appl Pharm Sci, 2020; 10(03):101-108. 